\title{
Unaltered sequence of dental, skeletal, and sexual maturity in domestic dogs compared to the wolf
}

\author{
Madeleine Geiger ${ }^{1 *}$, Karine Gendron², Florian Willmitzer ${ }^{3}$ and Marcelo R. Sánchez-Villagra ${ }^{4}$
}

\begin{abstract}
Background: It has been hypothesised that domestication altered the sequence of dental, skeletal, and sexual maturity of dogs when compared to their wolf ancestor. To test this we investigated a comprehensive sample of domestic dogs.

Methods: We documented the timing of completed eruption of permanent dentition into occlusion (dental maturity) and the timing of growth plate closure at the proximal humerus (skeletal maturity) in ontogenetic series of wolves and 15 domestic dog breeds. Data for 137 domestic dog and 64 wolf individuals were collected based on radiographs and examination of macerated bones.

Results: Our analyses show that domestic dogs exhibit a similar sequence of dental and skeletal maturity as the ancestral wolf. Although the absolute change of the age at attainment of sexual maturity is great in domestic dogs as compared to the wolf, the sequence of dental, skeletal, and sexual maturity is not altered as extensively, contradicting one previous hypothesis. Moreover, our data suggest that the chondrodystrophic dachshund attains skeletal maturity earlier than the non-chondrodystrophic breeds examined here.

Conclusions: Domestic dogs are more wolf-like in terms of the sequence of dental, skeletal, and sexual maturation than previously hypothesised. This implies that the domestication process and/or breed formation did not have a major impact on this sequence, although the absolute values of life history variables do have a greater range of variation than in the wild wolf.
\end{abstract}

Keywords: Tooth, Eruption, Growth plate, Epiphyseal fusion, Maturity

Abbreviations: CD, Chondrodystrophic; NCD, Non-chondrodystrophic; NMBE, Naturhistorisches Museum Bern, Switzerland; NRM, Naturhistoriska Riksmuseet, Stockholm, Sweden; VSB, Vetsuisse-Fakultät Bern (Departement für klinische Veterinärmedizin), Switzerland; ZMUZG, Zoologisches Museum der Universität Zürich, Switzerland

\section{Background}

Wolves living as commensals of humans at the beginning of the domestication process experienced changes in environmental conditions [1-3]. These changes may have included unpredictability of food supplies and decreasing interspecific competition, leading to accelerated maturation and increased fecundity [1-3]. Early domestic dogs are therefore hypothesised to have been smaller and to have attained sexual maturity earlier than wolves

\footnotetext{
* Correspondence: madeleine.geiger87@gmail.com

'Paläontologisches Institut und Museum, Universität Zürich, Zürich,

Switzerland

Full list of author information is available at the end of the article
}

[3]. It has also been proposed that, as a consequence, the sequence of somatic and sexual maturity was shifted in domestic dogs compared to wolves [4]. Specifically, in wolves dental maturity (completed emergence of the permanent dentition into occlusion) is followed by skeletal maturity (closure of the growth plates in long bones), which is then followed by sexual maturity [4]. In contrast, in domestic dogs it has been proposed that sexual maturity is attained earlier than skeletal and dental maturity, but the sequence of the latter two to one another is not shifted otherwise [4]. The early shift of sexual maturity with respect to dental and skeletal maturity in domestic dogs would also be expected, because 
uncertain nutritional supply does not affect the skeleton and teeth as greatly as it does sexual maturity [5]. The sequence of dental, skeletal, and sexual maturity in wolves, and changes of this sequence in domestic dogs, have to our knowledge not yet been investigated and reported in any study. Our study therefore aimed at testing whether this sequence is altered in domestic dogs compared to wolves, using a comprehensive dataset.

\section{Methods}

Our sample population included 137 domestic dogs (15 breeds) and 64 wolves; for the determination of the timing of dental maturity, dry skulls of 81 domestic dogs (11 breeds, Table 1) and 42 wolves were used; for the determination of the timing of skeletal maturity, radiographs of 56 domestic dogs ( 6 breeds, Table 1) and dry bones of 22 wolves were used. Dog breeds were chosen to represent a wide range of body size and proportions (Table 1).

Only specimens with a reported individual age of less than 14 months were used since domestic dogs and wolves are generally fully grown towards the end of their first year [6-14]. In the case of the domestic dogs and captive wolves, the age data were sourced from databases provided by the corresponding pet owners and zoological gardens. Individual ages of the wild wolves were approximated using information provided by cementum annuli counts and known breeding seasons and gestation times; estimates of the age of all wolves (in years) are based on cementum annuli counts [15] conducted by the Naturhistoriska Riksmuseet, Stockholm, where the wild wolves used in the present study are housed. We used these age estimates in association with an approximated date of birth: wolves in Finland, at about the same latitude as the middle part of Sweden $\left(\right.$ about $60^{\circ} \mathrm{N}$ ), where most Swedish wolves used in this study come from, were found to have breeding season in March [16, 17]. Adding a gestation time of 63 days, which is the average in wolves [17-23], the birth of the puppies falls within May. According to the birth records of 10 litters of captive wolves in Berne, Switzerland $\left(47^{\circ} \mathrm{N}\right)$, the mean birth date is the 8 May. Because the breeding season, and thus the date of whelping, gets later with increasing latitude $[16,17]$, the average birth date of the Swedish wolves is probably slightly later than that observed in Swiss wolves. Thus, for the sake of simplicity, we suggest the 15 May as the average birth date of the Swedish wolves. The age of the wolves from Naturhistoriska Riksmuseet was thus estimated as the cementum annuli count plus the difference between the 15 May and their date of death. This approach implies an error of plus/minus about a half a month for calculations of completed permanent dentition into occlusion as well as of closure of the proximal humeral growth plate. Individual ages in all specimens in this study were usually assessed in days and subsequently converted to months. Specimens exhibiting observable pathologies or specimens for which pathology affecting limb bones or the skull was reported in collection or patient databases were not included. Only specimens with a complete set of teeth were included, i.e., specimens with missing or reduced teeth were not considered.

Dry bones and skulls from the following institutions were examined to categorise status of dental eruption in domestic dogs and the wolf as well as of growth plate closure in the wolf: Naturhistorisches Museum Bern (NMBE); Naturhistoriska Riksmuseet, Stockholm (NRM); Zoologisches Museum der Universität Zürich (ZMUZH). Radiographs from the Vetsuisse-Fakultät Bern (VSB, Departement für klinische Veterinärmedizin) were examined to assess the investigation of growth plate closure in domestic dogs. Radiographs had been taken with a computed radiography system (CR, Fuijifilm, Dielsdorf, Switzerland) in the course

Table 1 Shoulder height, body proportions, and number of investigated specimens per domestic dog breed

\begin{tabular}{|c|c|c|c|c|c|c|}
\hline \multicolumn{3}{|l|}{ Dental maturity } & \multicolumn{4}{|l|}{ Skeletal maturity } \\
\hline Breed & Shoulder height (cm) & $n$ & Breed & Shoulder height (cm) & Body proportions & $n$ \\
\hline Bernese mountain dog & $58-70$ & 16 & Beagle & $33-41$ & NCD & 6 \\
\hline Boxer & $53-63$ & 5 & Bernese mountain dog & $58-70$ & NCD & 28 \\
\hline Fox terrier & $33-41$ & 4 & Chihuahua & $15-23$ & NCD & 5 \\
\hline French bulldog & 30 & 8 & Dachshund & $20-27$ & $C D$ & 7 \\
\hline German shepherd & $55-65$ & 10 & English bulldog & $31-40$ & NCD & 7 \\
\hline Golden retriever & $51-61$ & 6 & Standard poodle & $45-60$ & NCD & 3 \\
\hline Great Dane & $71-86$ & 9 & & & & \\
\hline Leonberger & $65-80$ & 5 & & & & \\
\hline Newfoundland & $63-74$ & 8 & & & & \\
\hline St. Bernard & $65-90$ & 6 & & & & \\
\hline Standard poodle & $45-60$ & 4 & & & & \\
\hline
\end{tabular}

$C D$ chondrodystrophic, NCD non-chondrodystrophic, $n$ number 
of medical diagnostic processes in accordance to standard hospital procedures, in standard positions [24]. Our investigations using these radiographs were thus retrospective.

The eruption stage of each tooth in the maxilla and the mandible was coded as described by Tappen et al. [25]: 1) unerupted, the tooth is not visible above the alveolus (Fig. 1a); 2) erupting, the tooth crown is visible above the alveolus, but not yet in occlusion (Fig. 1a); 3) erupted, the tooth is in the occlusal plane and the enamel-cementum junction is visible above the alveolus (Fig. 1b). Dental maturity was defined to be attained in a specimen if all incisors, premolars, and molars were fully erupted into the occlusal plane (stage 3 in all teeth). Additionally, the relative amount of eruption (eruption score) was calculated for every specimen: the sum of closure stages $(1,2$ or 3$)$ in all teeth was divided by the total number of teeth in the upper and the lower jaw (here 19). The resulting eruption score for every specimen thus lies between 1 (all permanent teeth are in stage 1) and 3 (dental maturity attained: all permanent teeth are in stage 3 ).

Closure of the proximal humeral growth plate was used as an indicator of skeletal maturity being the last postcranial plate to fuse in the comprehensive examination of the postcranium in wolves (Additional file 1). Each growth plate was scored as either open (stage 0, Fig. 1c) or closed (stage 1, Fig. 1d). Growth plates were considered closed in dry bones if the outer surface of the plate was at least in part obliterated [26]. On radiographs growth plates were considered closed if the radiolucent (black) line between epiphysis and metaphysis was no longer visible in at least one portion of the growth plate $[27,28]$. Age at attainment of female sexual maturity was derived from the literature [29-33]. Only females were considered due to the better availability of data on sexual maturity. Details on the specimens and discussion of methods are given in Additional file 1 and Additional file 2.

The here used ontogenetic series served to deduce age ranges at attainment of dental and skeletal maturity in domestic dogs and wolves [34, 35]. The estimated age ranges at (1) completed emergence of dentition into occlusion, (2) closure of the proximal humeral growth plate, and (3) attainment of sexual maturity were compared to one another in the domestic dogs and the wolf, respectively.

There has been disagreement as to whether there are breed specific differences of the age at attainment of dental, skeletal, and sexual maturity within domestic dogs (for details see Additional file 2). Specifically, it has been argued that dental maturity is correlated with breed [36] and body size [37-43]; it has been hypothesised variously that skeletal maturity is correlated with breed $[44,45]$ nutritional condition [37, 46], sex [29, 44, 47-51], age at time of neutering of puppies [28], and relative limb proportions [27, 44, 52, 53], i.e., chondrodystrophy (disturbed cartilage and endochondral bone growth, resulting in disproportionately short, thickened, and curved long bones [54-56]); sexual maturity has been argued to be correlated with body size [29, 57-61],
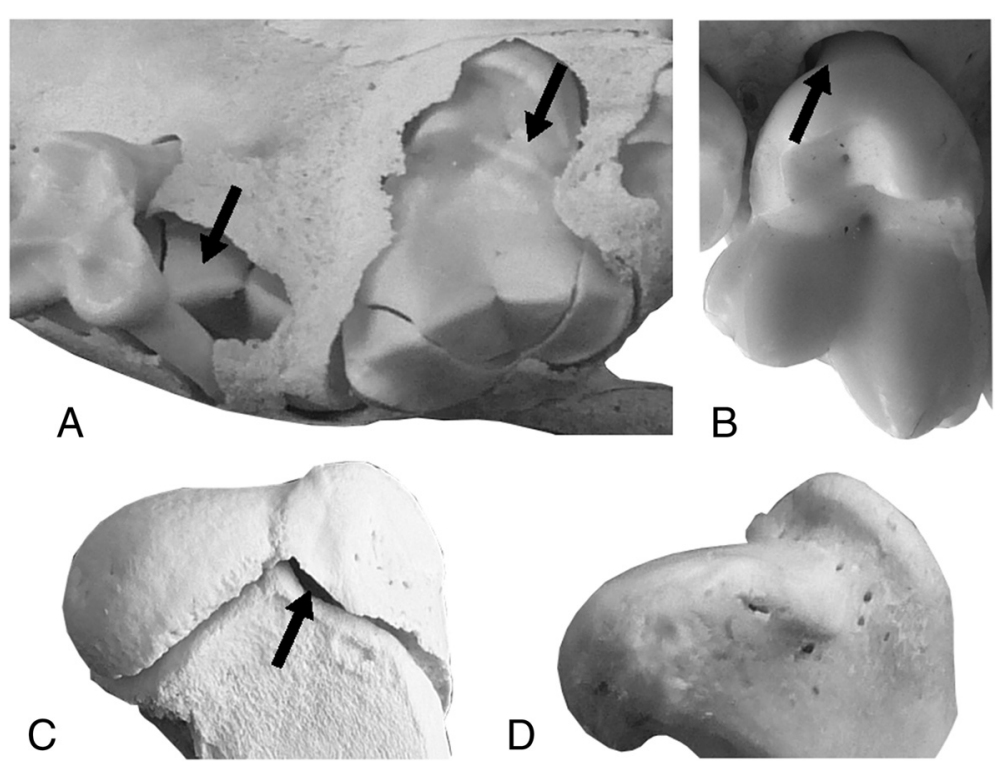

Fig. 1 Tooth eruption (a, b) and growth plate closure (c, d) stages. a Stage 1 (left arrow), unerupted, the tooth is not visible above the alveolus; stage 2 (right arrow), erupting, the tooth crown is visible above the alveolus, but not yet in occlusion. $\mathbf{b}$ Stage 3, erupted, the tooth is in the occlusal plane and the enamel-cementum junction (arrow) is visible above the alveolus. c Stage 0, open growth plate (arrow). d Stage 1, closed, outer surface is at least in part obliterated by bone 
breed, and housing conditions [57, 58]. Our sampling included domestic dogs of a great range of body sizes (Table 1). Further, both sexes were included and neutered specimens were not considered. Moreover, our domestic dog sample contained only specimens from a middle European origin and we thus considered the living environment rather homogenous. Therefore, many of the variables that might affect the age at attainment of dental and skeletal maturity are unlikely to have biased our estimates. Nevertheless, the influence of two variables on the estimates has been tested here. First, it has been tested whether chondrodystrophy is correlated with the age at attainment of skeletal maturity. Our sample contained one chondrodystrophic breed, the dachshund $[62,63]$ (Table 1). We examined whether the attainment of skeletal maturity in this chondrodystrophic breed is different from non-chondrodystrophic breeds. Second, we tested whether differences in body size are correlated with the age at attainment of sexual maturity. The here used records of the mean age at attainment of sexual maturity and adult female body weight in 43 domestic dogs breeds ranging from around $3 \mathrm{~kg}$ (Affenpinscher) to around $68 \mathrm{~kg}$ (St. Bernard) were obtained from Johnston et al. [29]. To determine if there is a correlation between body size and age at attainment of sexual maturity, a non-parametric Spearman's correlation was calculated using $R$ version 2.15 .1 and RStudio version 0.98 .501 . Since body size was found to be not correlated with the estimate of attainment of sexual maturity (see Results), no corrections of our data was conducted in this regard.

\section{Results}

Our data suggest that in wolves, dental maturity is attained at 4-6 months (Fig. 2a, Additional file 1) and skeletal maturity at 10-12 months (Fig. 2b, Additional file 1). On the basis of examinations of hormone levels, follicle development, and condition of uteri, it has been stated that reproduction in wolves usually does not commence before the 22 month of postnatal life [31,32]. Reproductive activity of wolves in the first year of life has, however, been reported, but seems to occur only occasionally $[14,30,33]$. An extremely late onset of reproduction (five or six years) is also known to occur $[14,64]$.

We found evidence that in domestic dogs, dental maturity is attained at 4-6 months (Fig. 2a, Additional file 1) and skeletal maturity at 10-11 months (only if considering non-chondrodystrophic breeds, see below) (Fig. 2b, Additional file 1). The age at attainment of sexual maturity ranges from around seven months (border collie, Cavalier King Charles spaniel) to 21 months (Italian greyhound), with a mean of about 12.5 months across all reported breeds [29].
There was a non-significant correlation between mean adult female body mass and age at attainment of sexual maturity $\left(\mathrm{r}_{\mathrm{S}}=0.064, P=0.682\right)$. We found evidence that the attainment of skeletal maturity in the chondrodystrophic dachshund occurs at 8-9 months (Additional file 1), an age at which none of the here investigated non-chondrodystrophic domestic dogs exhibited a closed proximal humeral growth plate and thus skeletal maturity (Additional file 1). The dataset supporting this article has been uploaded as part of the supplementary information (Additional file 1).

\section{Discussion}

Estimated age at attainment of dental maturity in domestic dogs and wolves as determined in this study (4-6 months) is in agreement with previous reports of values ranging from 6 to 7 months in the German Shepherd [39], 5.4-8.4 months in the bull terrier [43], and 6-7 months in wolves [14]. Slightly lower estimates in this study compared to the literature are probably the consequence of the exclusion of the canine teeth (Additional file 2). Our estimates of age at attainment of skeletal maturity in domestic dogs (10-11 months) and the wolf (10-12 months) are in agreement with published ranges of 8.5 to 13.75 months in the domestic $\operatorname{dog}[27,44,45,47,48,50,51,65-67]$ and 10.8 to 12.3 months in the wolf [50], respectively. Our results show that there is no shift of the sequence of attainment of skeletal maturity in respect to dental maturity in domestic dogs compared to wolves. This finding substantiates previous hypotheses $[50,68]$. We would like to point out here that the general applicability of our results is restricted by the sample, which is limited due to several factors: first, due to a lack of associated skulls and postcranial skeletons, the age estimates for dental and skeletal maturity are based on different specimens and joining of breeds (see also Additional file 2); second, the different extant 'subspecies' of the wolf were not considered for this study (Additional file 1) since it is literally impossible to sample the original population(s) of wolves which was (were) domesticated [69]. Third, our methodology does not allow for continuous data that can be easily statistically tested (see below).

It has been discussed if the age at attainment of skeletal maturity is associated with chondrodystrophy, a congenital disturbance which affects mainly the cartilage and has a negative impact on the growth of endochondral bone, and thus also long bones of limbs [27, 44, 52, 53]. Our result supports the view that the age at attainment of skeletal maturity in the chondrodystrophic dachshund is attained earlier (8-9 months) than in nonchondrodystrophic breeds. However, the early attainment of skeletal maturity in the chondrodystrophic breed does not alter the sequence of dental and skeletal 

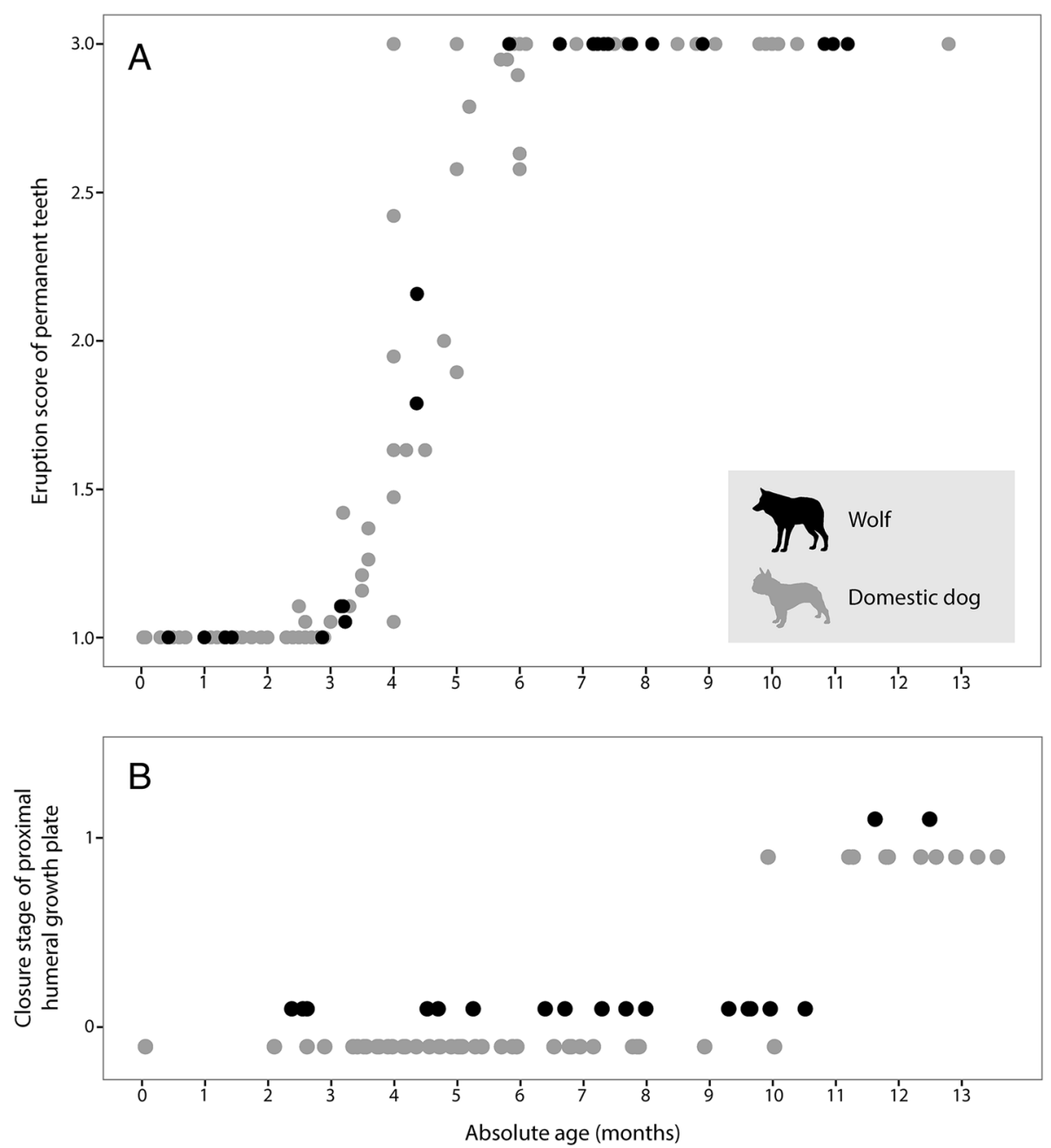

Fig. 2 Stages of tooth eruption (a) and proximal humeral growth plate closure (b) in the investigated wolves and domestic dogs of different absolute ages. The data suggest that dental maturity (a) is attained at $4-6$ months in wolves and domestic dogs and skeletal maturity (b) is attained at $10-12$ months in wolves and $10-11$ months in domestic dogs (only non-chondrodystrophic breeds). There are no extensive differences between dogs and wolves. Eruption scores (a) were calculated as the sum of the eruption stages of all teeth $(1,2$ or 3 ; Fig. 1) divided by the total number of examined teeth. The resulting eruption score thus lays between 1 (all permanent teeth are in stage 1) and 3 (dental maturity attained: all permanent teeth fully erupted in stage 3). Proximal humeral growth plates were scored as either open (stage 0) or closed (stage 1, Fig. 1). Raw data are provided in Additional file 1

maturity in this breed. Further, there is evidence for a relationship between epiphyseal growth plate closure and the attainment of sexual maturity. It has been found that oestrogen treatment accelerates senescence of growth plates in ovariectomised rabbit tibiae, leading to early growth plate closure relative to untreated ovariectomised specimens [70]. Effects of oestrogen on growth plate physiology have also been found in other species (for a review see [71]). Similarly, as described above, it has been shown that gonadectomy, and thus potentially lower levels of oestrogens, delays growth plate closure in domestic dogs [28]. As oestrogen is crucial for the development of sexual organs, the attainment of skeletal and sexual maturity may be interrelated by means of this hormone.

It has been hypothesised that in wild canids, dental maturity and skeletal maturity were attained before sexual maturity, with dental maturity preceding skeletal maturity (dental - skeletal - sexual) [4]. In domestic dogs, this sequence was hypothesised to have reversed to sexual - dental - skeletal due to changed environmental conditions during domestication [4]. Our findings support this hypothesis for the wolf: dental maturity is attained at 4-6 months, followed by skeletal maturity at 10-12 months, and finally sexual maturity at about 22 months on average. However, it is important to 
note that in some wolves, skeletal and sexual maturity might overlap. This overlap could for example occur in wolves that attain sexual maturity with nine or ten months (see below) [14, 30, 33]. Domestic dogs have been found to attain dental and skeletal maturity at a similar age as wolves, but the age at attainment of sexual maturity is generally lower than in wolves (7-21 months). It has therefore to be expected that the sequence in domestic dogs with comparably late attainment of sexual maturity is similar as in wolves (dental skeletal - sexual). In other breeds with an average or low age at attainment of sexual maturity, on the other hand, there might be a heterochronic shift of sexual maturity in respect of skeletal maturity (dental - sexual skeletal), or sexual and skeletal maturity occur simultaneously (dental - skeletal/sexual). According to our estimates it is, however, unlikely that sexual maturity would ever be attained before the attainment of dental maturity in domestic dogs.

Reasons for the relatively early attainment of sexual maturity in domestic dogs compared to wolves may lie in the social system of these two forms. Due to suppression of sexual maturity in subordinate pack members through dominance of the alpha-female, young wolves breed mostly only after they disperse from their natal pack, at 11-24 months of age or later [72]. In domestic dogs there is no such reproduction control, and sexual maturity is attained within the first year or up to 1.5 years [73]. The early onset of reproduction in domestic dogs might thus be the result of the absence of a complex social system, such as that found in wolves, and a loss of susceptibility to social suppression [30, 74, 75]. This latter element has been speculated to be based on the close proximity of domestic dogs to humans, with subsequent ample opportunities to scavenge, which has made the dependence of domestic dogs on one another, and thus monogamy and true pack behaviour, unnecessary [74].

\section{Conclusions}

While we detected no change in the age at attainment of dental and skeletal maturity in domestic dogs as compared to wolves, the change in the absolute age at the attainment of sexual maturity is extensive. Although the relatively early attainment of sexual maturity in domestic dogs compared to wolves signifies a change in the hypothesised direction, it does not result in a sequence change of dental, skeletal, and sexual maturity as extensive as previously hypothesised, with sexual maturity preceding dental and skeletal maturity in domestic dogs [4]. Preservation of life history variables within species and clades has been reported [76] and our study substantiates this finding.

With the sample at hand it is not possible to corroborate that the observed pattern has been established during the early domestication process or is the result of the more recent establishment of modern breeds. Future research on skeletal and dental maturity in dogs during the early domestication process will require ontogenetic series of fully articulated prehistoric specimens. Alternatively, pariah dogs could serve as an approximation for domesticated dogs during the early domestication process. Pariah, or stray, dogs, are ownerless dogs that depend indirectly on humans for food and shelter [74]. As such, they are human commensals, i.e., they take advantage of elements of the human niche, and therefore mirror the commensal relationship that has been suggested for humans and wolves/domestic dogs during the early domestication process $[77,78]$. To set the research on the attainment of somatic and sexual maturity in a much wider context, more domesticated species should be considered. For example, the examination of penned pigs versus free ranging pigs versus wild boar would be worthwhile (as an example see Evin et al. [79]). Especially useful would be the investigation of species that have been domesticated relatively recently and were subject to a human directed, immediate, and rapid form of domestication, using established knowledge about previous domestication processes ('directed' pathway) [78]. In such species, e.g. golden hamster (Mesocricetus auratus), the ancestral wild populations are likely to be better known and extant, unlike those for some 'ancient' domesticates, such as dogs. Moreover, the examination of domesticates of various body sizes would make possible the investigation of the order of dental, skeletal, and sexual maturity in relation to other life history traits, for example longevity, a kind of study also applicable to island forms and their known similar pattern of evolution to domesticated forms [80]. It has been suggested that species with a relatively short lifespan, e.g., small rodents, attain sexual maturity only after dental and skeletal maturity (dental - skeletal - sexual), whereas sexual maturity is attained earlier than dental and skeletal maturity (sexual - dental - skeletal) in mammals with a relatively long lifespan, e.g. great apes $[4,81]$. Although this pattern was suggested to be only valid for wild species, and not for domestic forms, these relationships require more empirical tests. Finally, studies on the investigation of somatic versus sexual maturity would benefit from an improved methodology. This would include a longitudinal growth series of domestic dogs and wolves, for which CT-scans of the same individuals would be produced throughout their development from birth to adulthood, maybe also under different environmental conditions (e.g., food supply, nutritional content of food). These CT-cans could be used to measure percentages of growth plate fusion and tooth eruption and therefore provide, together with measures of total bone length and total tooth size, better continuous data to be 
tested statistically. Such an extensive study was beyond the possibility of the project presented here and may not yield different results.

\section{Additional files}

Additional file 1: Tooth eruption and growth plate closure stages in the wolves and domestic dogs examined in this study. (XLSX $34 \mathrm{~kb}$ )

Additional file 2: Details and discussion on data acquisition, and variation of dental, skeletal, and sexual maturity within domestic dogs. (DOCX $20 \mathrm{~kb}$ )

\section{Acknowledgments}

We thank Marc Nussbaumer (Albert-Heim-Foundation), Paul Schmid (NMBE), Daniela Kalthoff (NRM), and Marianne Haffner and Barbara Oberholzer (ZMUZH) for access to collections, Johann Lang (VSB) and Patrick R. Kircher (Tierspital Universität Zürich) for access to radiographs and for discussions, Juan Carrillo for methodological advice, and three reviewers for valuable comments that helped to improve the manuscript.

\section{Funding}

This work has been supported by the Forschungskredit FK-13-088 to MG and by the Swiss NSF grant 31003A_149605 to MRSV.

\section{Availability of data and materials}

The datasets supporting the conclusions of this article are included within the articles additional files.

\section{Authors' contributions}

MG carried out the acquisition of data and data analysis, participated in the conception and design of the study, and drafted the manuscript; KG and FW participated in data sampling and critical revision of the draft for factual content. MRSV participated in the conception and design of the study and critical revision of the draft for intellectual content. All authors gave final approval for publication

\section{Competing interests}

The authors declare to have no competing interests.

\section{Consent for publication}

Not applicable.

\section{Ethics approval and consent to participate}

Not applicable.

\section{Author details}

${ }^{1}$ Paläontologisches Institut und Museum, Universität Zürich, Zürich, Switzerland. 'Departement für klinische Veterinärmedizin, Vetsuisse-Fakultät, Universität Bern, Bern, Switzerland. ${ }^{3}$ Departement für Kleintiere, Bildgebende Diagnostik, Vetsuisse-Fakultät, Universität Zürich, Zürich, Switzerland. ${ }^{4}$ Paläontologisches Institut und Museum, Universität Zürich, Zürich, Switzerland.

\section{Received: 26 January 2016 Accepted: 18 August 2016}

Published online: 22 August 2016

\section{References}

1. Clutton-Brock J. Origins of the dog: domestication and early history. In: Serpell J, editor. The domestic dog: its evolution, behaviour, and interactions with people. Cambridge: Cambridge University Press; 1995. p. 7-20.

2. Morey DF. The early evolution of the domestic dog. Am Sci. 1994;82:336-47.

3. Tchernov E, Horwitz LK. Body size diminution under domestication: unconscious selection in primeval domesticates. J Anthropol Archaeol. 1991;10:54-75

4. Shigehara N. Epiphyseal union, tooth eruption, and sexual maturation in the common tree shrew, with reference to its systematic problem. Primates. 1980;21:1-19.
5. Garn SM, Lewis AB, Kerewsky RS. Genetic, nutritional, and maturational correlates of dental development. J Dent Res. 1965;44:228-42.

6. Schubert D. Untersuchungen zum postnatalen Skelett- und Körperwachstum von Hunden der Rasse West Highland White Terrier. Doctoral thesis. Leipzig: Universität Leipzig, Veterinärmedizinische Fakultät; 2011.

7. Kaiser M. Untersuchungen zum postnatalen Skelett- und Körperwachstum von Hunden der Rasse Berner Sennenhund. Doctoral thesis. Leipzig: Universität Leipzig, Veterinärmedizinische Fakultät; 2003.

8. Böhme U. Untersuchungen zur postnatalen Entwicklung des Skelettes und der Körpermasse beim Hund. Doctoral thesis. Leipzig: Universität Leipzig, Veterinärmedizinische Fakultät; 1994.

9. Baumbach B. Untersuchungen zum postnatalen Skelett- und Körperwachstum von Hunden der Rasse Rottweiler. Doctoral thesis. Leipzig: Universität Leipzig, Veterinärmedizinische Fakultät; 1999.

10. Kreher M. Untersuchungen zum postnatalen Skelett- und Körperwachstum von Hunden der Rasse Drathaar-Foxterrier. Doctoral thesis. Leipzig: Universität Leipzig, Veterinärmedizinische Fakultät; 2005.

11. Schulze A, Ritscher D, Salomon FV. Body weight growth of the Great Dane. Kleintierpraxis. 1997:42:967-72.

12. Salomon FV, Schulze A, Bohme U, Arnold U, Gericke A, Gille U. Das postnatale Wachstum des Skelettes und der Körpermasse beim Beagle. Anat Histol Embryol. 1999;28:221-8.

13. Hawthorne AJ, Booles D, Nugent PA, Gettinby G, Wilkinson J. Body-weight changes during growth in puppies of different breeds. J Nutr. 2004; 134:2027S-30S

14. Kreeger TJ. The internal wolf: physiology, pathology, and pharmacology. In: Mech LD, Boitani L, editors. Wolves: behavior, ecology, and conservation. Chicago \& London: University of Chicago Press; 2003. p. 192-217.

15. Goodwin EA, Ballard WB. Use of tooth cementum for age determination of gray wolves. J Wildlife Manage. 1985;49:313-6.

16. Mech LD. Breeding season of wolves, Canis lupus, in relation to latitude. Can Field-Nat. 2002;116:139-40.

17. Mech LD. The wolf: the ecology and behavior of an endangered species. Garden City, New York: Natural History Press; 1970

18. Asdell SA. Patterns of mammalian reproduction. Ithaca: Cornell University Press; 1964.

19. Bekoff M, Diamond J, Mitton JB. Life history patterns and sociality in canids: body size, reproduction, and behavior. Oecologia (Berl). 1981:50:386-90.

20. Iljin NA. Wolf-dog genetics. J Genet. 1941;42:359-414.

21. Mech LD. Canis lupus. ASM. 1974:37:1-6.

22. Peters G. Canis lupus Linnaeus, 1758 - Wolf. In: Stubbe M, Krapp F, editors Handbuch der Säugetiere Europas. Band 5: Raubsäuger - Carnivora (Fissipedia). Teil 1: Canidae, Ursidae, Procyonidae, Mustelidae 1. Wiesbaden: Aula-Verlag; 1993. p. 47-106.

23. Young SF, Goldman EA. The wolves of North America. New York: Dover Publications; 1944

24. Lavin LM. Radiography in veterinary technology. St. Louis: Saunders Company; 1999

25. Tappen NC, Severson A. Sequence of eruption of permanent teeth and epiphyseal union in New World monkeys. Folia Primatol. 1971;15:293-312.

26. Geiger M, Forasiepi AM, Koyabu D, Sânchez-Villagra MR. Heterochrony and post-natal growth in mammals - an examination of growth plates in limbs. J Evol Biol. 2014:27:98-115.

27. Hanlon GF. Normal and abnormal bone growth in the dog. Vet Radiol Ultrasound. 1962:3:13-5.

28. Salmeri KR, Bloomberg MS, Scruggs SL, Shille V. Gonadectomy in immature dogs: effects on skeletal, physical, and behavioral development. J Am Vet Med Assoc. 1991;198:1193-203.

29. Johnston SD, Kustritz MVR, Olson PS. Canine and feline theriogenology. Philadelphia: Saunders; 2001.

30. Seal US, Plotka ED, Packard JM, Mech LD. Endocrine correlates of reproduction in the wolf. 1. Serum progesterone, estradiol and LH during the estrous cycle. Biol Reprod. 1979;21:1057-66.

31. Parker GR, Luttich S. Characteristics of the wolf (Canis lupus labradorius Goldman) in northern Quebec and Labrador. Arctic. 1986;39:145-9.

32. Rausch RA. Some aspects of the population ecology of wolves. Alaska Am Zool. 1967;7:253-65.

33. Medjo DC, Mech LD. Reproductive activity in nine- and ten-month-old wolves. J Mammal. 1976;57:406-8.

34. Kohn LAP, Olson P, Cheverud JM. Age of epiphyseal closure in tamarins and marmosets. Am J Primatol. 1997:41:129-39. 
35. Glassman DM. Growth and development in the saddle-back tamarin: the sequence and timing of dental eruption and epiphyseal union. Am J Primatol. 1983:5:51-9.

36. Scott JP, Fuller JL. Genetics and the social behavior of the dog. Chicago: University of Chicago Press; 1965.

37. Huidekoper RS. Age of the domestic animals: being a complete treatise on the dentition of the horse, ox, sheep, hog, and dog, and on the various other means of determining the age of these animals. Philadelphia, London: F. A. Davis; 1891

38. Bell AF. Dental disease in the dog. J Small Anim Pract. 1965;6:421-8.

39. Habermehl K-H. Die Altersbestimmung bei Haus- und Labortieren. Berlin: Parey; 1975.

40. Liautard A. How to tell the age of domestic animals. New York: William R. Jenkins, Veterinary Publisher and Bookseller; 1885.

41. Wehrend A. Neonatologie beim Hund - Von der Geburt bis zum Absetzen. Hannover: Schlütersche Verlagsgesellschaft; 2013.

42. Evans HE. Miller's Anatomy of the Dog. Philadelphia: Saunders; 1993.

43. Arnall L. Some Aspects of Dental Development in the Dog-II. Eruption and Extrusion. J Small Anim Pract. 1960;1:259-67.

44. Hare WC. The age at which epiphyseal union takes place in the limb bones of the dog. Wien Tierarztl Monatsschr, Festschrift Schreiber. 1960; 224-43.

45. Hare WCD. Radiographic anatomy of the canine pectoral limb. II. Developing limb. J Am Vet Med Assoc. 1959;135:305-10.

46. Wayne HR, Shirer JF. Normal and abnormal growth of the distal foreleg in large and giant dogs. Vet Radiol Ultrasound. 1965;6:50-64.

47. Sumner-Smith G. Observations on epiphyseal fusion of the canine appendicular skeleton. J Small Anim Pract. 1966;7:303-11.

48. Schroeder M. Beitrag zur Entwicklung des Skelettes der Vordergliedmasse beim Deutschen Schäferhund. Doctoral thesis. München: LudwigMaximilians-Universität München, Fachbereich Tiermedizin; 1978.

49. Widmer W. Beitrag zur Entwicklung des Skeletts der Hintergliedmasse beim Deutschen Schäferhund. Doctoral thesis. München: Ludwig-MaximiliansUniversität München, Fachbereich Tiermedizin; 1978.

50. Wiechering G. Untersuchungen über den Epiphysenfugenschluss bei Wölfen und Haushunden. Schriften aus der Archäologisch-Zoologischen Arbeitsgruppe Schleswig-Kiel. 1981.

51. Smith RN, Allcock J. Epiphysial fusion in the greyhound. Vet Rec. 1960;72:75-9.

52. Hitz D. Untersuchungen über Skelett- und Gelenkveränderungen beim Basset-Hound. Doctoral thesis.Zürich: Universität Zürich, 1973.

53. Owens JM, Biery DN, Hartung K. Röntgenbildinterpretation für den Kleintierpraktiker. Stuttgart: Enke; 1989.

54. Kealy JK, McAllister H, Graham JP. Diagnostic radiology and ultrasonography of the dog and cat. Saunders: St. Louis; 2011.

55. Jezyk PF. Constitutional disorders of the skeleton in dogs and cats. In: Newton CD, Nunamaker DM, editors. Textbook of Small Animal Orthopaedics. Ithaca, New York: International Veterinary Information Service; 1985.

56. Almlöf J. On achondroplasia in the dog. Zbl Vet Med. 1961;8:43-56.

57. Cupps PT. Reproduction in domestic animals. San Diego: Academic; 1991.

58. England GCW. Dog breeding, whelping and puppy care. West-Sussex: Wiley-Blackwell; 2013.

59. England GCW, Av H. BSAVA manual of canine and feline reproduction and neonatology. Cheltenham: British Small Animal Veterinary Association; 2010.

60. Root Kustritz MV. Clinical canine and feline reproduction - evidence-based answers. lowa: Wiley-Blackwell; 2010.

61. Darwin C. The variation of animals and plants under domestication. Charleston: BiblioBazaar; 1868.

62. Parker HG, VonHoldt BM, Quignon P, Margulies EH, Shao S, Mosher DS, Spady TC, et al. An expressed fgf4 retrogene is associated with breeddefining chondrodysplasia in domestic dogs. Science. 2009;325:995-8.

63. Hansen $\mathrm{H}-\mathrm{J}$. A pathologic-anatomical interpretation of disc degeneration in dogs. Acta Orthop. 1951;20:280-93.

64. Zimen E. Der Hund. München: Goldmann; 1988

65. Chapman WL. Appearance of ossification centers and epiphysial closures as determined by radiographic techniques. J Am Vet Med Assoc. 1965;147:138-41.

66. Seoudi K. X-ray examination of epiphyseal union as an aid to the estimation of the age in dogs. Br Vet J. 1947;103:150-5.

67. Yonamine H, Ogi N, Ishikawa T, Ichiki H. Radiographic studies on skeletal growth of the pectoral limb of the beagle. Jpn J Vet Sci. 1980;42:417-25.

68. Habermehl K-H. Altersbestimmung bei Wild-und Pelztieren. Hamburg, Berlin: Verlag Paul Parey; 1985.
69. Larson G, Bradley DG. How much is that in dog years? The advent of canine population genomics. Plos Genet. 2014;10:e1004093.

70. Weise M, De-Levi S, Barnes KM, Gafni Rl, Abad V, Baron J. Effects of estrogen on growth plate senescence and epiphyseal fusion. Proc Natl Acad Sci U S A. 2001;98(12):6871-6.

71. Van der Eerden BCJ, Karperien M, Wit JM. Systemic and local regulation of the growth plate. Endocr Rev. 2003; 782-801.

72. Mech LD, Boitani L. Wolves: behavior, ecology, and conservation. Chicago and London: University of Chicago Press; 2003.

73. Lord K, Feinstein M, Smith B, Coppinger R. Variation in reproductive traits of members of the genus Canis with special attention to the domestic dog (Canis familiaris). Behav Process. 2013;92:131-42.

74. Spotte S. Societies of wolves and free-ranging dogs. Cambridge: Cambridge University Press; 2012.

75. Price EO. Behavioral development in animals undergoing domestication. Appl Anim Behav Sci. 1999;65:245-71.

76. Clauss M, Dittmann MT, Mueller DWH, Zerbe P, Codron D. Low scaling of a life history variable: Analysing eutherian gestation periods with and without phylogeny-informed statistics. Mamm Biol. 2014;79:9-16.

77. Vigne JD. The origins of animal domestication and husbandry: a major change in the history of humanity and the biosphere. C R Biol. 2011;334(3):171-81.

78. Zeder MA. Pathways to animal domestication. In: Gepts P, Famula TR, Bettinger RL, Brush SB, Damania AB, McGuire PE, Qualset CO, editors. Biodiversity in agriculture: domestication, evolution, and sustainability. New York: Cambridge University Press; 2012. p. 227-59.

79. Evin A, Dobney K, Schafberg R, Owen J, Vidarsdottir U, Larson G, Cucchi T. Phenotype and animal domestication: A study of dental variation between domestic, wild, captive, hybrid and insular Sus scrofa. BMC Evol Biol. 2015;15(1):1

80. Sánchez-Villagra MR, Geiger M, Schneider RA. The taming of the neural crest: a developmental perspective on the origins of morphological covariation in domesticated mammals. R Soc Open Sci. 2016;3:160107.

81. Smith BH. Life history and the evolution of human maturation. Evol Anthropol. 1992;1(4):134-42.

\section{Submit your next manuscript to BioMed Central and we will help you at every step:}

- We accept pre-submission inquiries

- Our selector tool helps you to find the most relevant journal

- We provide round the clock customer support

- Convenient online submission

- Thorough peer review

- Inclusion in PubMed and all major indexing services

- Maximum visibility for your research

Submit your manuscript at www.biomedcentral.com/submit
Biomed Central 